\title{
Management of eclampsia in the accident and emergency department
}

\author{
Philip T Munro
}

\begin{abstract}
Eclampsia is defined as the occurrence of seizures in pregnancy or within 10 days of delivery, accompanied by at least two of the following features documented within 24 hours of the seizure: hypertension, proteinuria, thrombocytopenia or raised aspartate amino transferase. Eclampsia complicates approximately one in 2000 pregnancies in the United Kingdom and it remains one of the main causes of maternal death.

Up to $38 \%$ of cases of eclampsia can occur without premonitory signs or symptoms of pre-eclampsia-that is, hypertension, proteinuria, and oedema. Only $38 \%$ of eclamptic seizures occur antepartum; $18 \%$ occur during labour and a further $44 \%$ occur postpartum. Rare cases of eclampsia have occurred over a week after delivery.

Outcome is poor for mother and child. Almost one in 50 women suffering eclamptic seizures die, $23 \%$ will require ventilation and $35 \%$ will have at least one major complication including pulmonary oedema, renal failure, disseminated intravascular coagulation, HELLP syndrome, acute respiratory distress syndrome, stroke, or cardiac arrest. Stillbirth or neonatal death occurs in approximately one in 14 cases of eclampsia.

Up to one third of eclamptic seizures occur out of hospital. For this reason, initial management may involve accident and emergency departments. Early involvement of senior obstetric staff is crucial. Optimal emergency management of seizures, hypertension, fluid balance and subsequent safe transfer is essential to minimise morbidity and mortality.

(F Accid Emerg Med 2000;17:7-11)
\end{abstract}

Keywords: eclampsia; magnesium sulphate; seizures; pregnancy

Eclampsia, meaning literally "to shine forth", complicates approximately one in 2000 pregnancies and is one of the main causes of maternal death in the United Kingdom. ${ }^{1}$ The cause is a pregnancy specific, underlying multiorgan disorder involving vascular endothelial damage, intravascular coagulation, and vasoconstriction leading to end organ ischaemia. There may be a variety of presentations and classic features are not always present. Changes have occurred in the recommended treatment for eclamptic seizures and are considerably different from other seizure disorders (including management of hypertension and careful fluid balance). As one third of cases occur out of hospital, eclampsia should be considered in the differential diagnosis in any pregnant woman presenting to the accident and emergency $(A \& E)$ department with seizures.

\section{Definition}

An early definition of eclampsia was the occurrence of seizures in the presence of preeclampsia (shown by hypertension, proteinuria, and oedema occurring after 20 weeks' gestation). Current definitions place less reliance on the presence of pre-eclampsia as eclampsia can develop without preceding symptoms or signs in up to $38 \%$ of cases. $^{2}$

The UK Eclampsia Trial ${ }^{1}$ definition consisted of: Seizures occurring in pregnancy or within 10 days of delivery and with at least two of the following features documented within 24 hours of the seizure:

- Hypertension diastolic blood pressure (DBP) of at least $90 \mathrm{~mm} \mathrm{Hg}$ (if DBP less than 90 $\mathrm{mm} \mathrm{Hg}$ on booking visit) or DBP increment of $25 \mathrm{~mm} \mathrm{Hg}$ above booking level.

- Proteinuria one "plus" or at least $0.3 \mathrm{~g} / 24 \mathrm{~h}$.

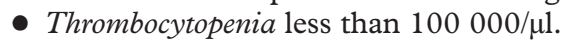

- Raised aspartate amino transferase (AST) greater than 42 IU/1.

Pre-eclampsia is a pregnancy specific, multiorgan disorder. The main features are hypertension, proteinuria, and generalised oedema occurring after 20 weeks' gestation. Other common features include haemoconcentration, hypoalbuminaemia, hepatic dysfunction, coagulation problems and hyperuricaemia. Pre-eclampsia usually regresses within 48 hours of delivery. Hypertension in this setting is usually taken as DBP $15 \mathrm{~mm} \mathrm{Hg}$ higher than DBP in early pregnancy. If previous values are not known, a blood pressure of greater than $140 / 90 \mathrm{~mm} \mathrm{Hg}$ is considered significant. Table 1 shows indicators of severe preeclampsia.

Pre-eclampsia may progress to eclamptic seizures without warning, although the above features may herald the onset of fits.

\section{Table 1 Indicators of severe pre-eclampsia}

- Systolic blood pressure $>160 \mathrm{~mm} \mathrm{Hg}$

- DBP >110 mm Hg

- Proteinuria ++ or +++

- Serum creatinine $>1.2 \mathrm{mg} / \mathrm{dl}$

- Platelets $<100000 / \mu 1$

- Increased AST or ALT

- Epigastric pain

- Headache, other cerebral or visual symptom

- Retinal exudates, haemorrhages, or papilloedema - Pulmonary oedema 
Incidence

A prospective descriptive survey of every case of eclampsia in the UK was carried out in 1992. ${ }^{1}$ Two hundred and seventy nine consultant led obstetric units were surveyed. Five hundred and eighty two possible cases were reported and 383 were subsequently confirmed as cases of eclampsia. This gave a rate of 4.9 per 10000 maternities. This incidence is similar to that reported in the USA in $1983-1986$ of 4.3 per $10000 .^{3}$ Sixty eight per cent of seizures occurred in hospital; $44 \%$ were postpartum; $18 \%$ were intrapartum. The remainder were antepartum.

Of the postpartum cases, 20 seizures occurred more than 48 hours after delivery and three occurred after seven days.

\section{Pathophysiology}

Pre-eclampsia/eclampsia is thought to result from abnormal placental development. Major pathological changes occur in the placental vascular bed resulting in placental ischaemia. An alteration in the ratio of prostacyclin and thromboxane occurs along with platelet aggregation, thrombin activation, and fibrin deposition in maternal systemic vascular beds. Increased capillary permeability and hypoalbuminaemia also occur. A combination of profound vasospasm and thrombosis causes dysfunction of almost all organ systems. ${ }^{2}$

Pre-disposing factors for pre-eclampsia include nulliparity, multiple gestations, extremes of age (teenagers three times more likely than older women), diabetes mellitus, hydatidiform mole, fetal hydrops, and family history. ${ }^{14}$

In pre-eclampsia, there are exaggerated responses to angiotensin II, catecholamines, and vasopressin. ${ }^{2}$ Intravascular volume is reduced. Seizures are thought to be the result of cerebral vasospasm and endothelial damage leading to ischaemia, microinfarcts, and oedema. ${ }^{25}$

Bleeding time is frequently increased in severe pre-eclampsia, although standard coagulation tests such as prothrombin time and partial thromboplastin time may be normal. ${ }^{2}$ The cause of this is uncertain but increased levels of von Willebrand's factor and other unknown substances may be implicated. ${ }^{6}$

\section{Presentation of eclampsia}

In the UK Eclampsia Trial, ${ }^{1} 18 \%$ of women suffering eclamptic seizures were parous and had no previous history of pre-eclampsia or eclampsia. Seizures were significantly more likely in teenagers and those with multiple pregnancies - that is, twins, triplets, etc. Making a diagnosis of pre-eclampsia in the $\mathrm{A} \& \mathrm{E}$ department may be difficult as the features of hypertension, proteinuria, and oedema can occur individually as part of other diseases and in normal pregnancy. ${ }^{4}$ Table 2 summarises the incidence of proteinuria, hypertension, and symptoms before the onset of seizure. Thirty eight per cent had their first fit outside the hospital and $49 \%$ of women with eclampsia had multiple seizures. A recent case series suggested that all women at more than 20 weeks' gestation presenting with epigastric or right
Table 2 Presentation of eclampsia (UK Eclampsia Trial)

Features documented at most recent antenatal visit

- Proteinuria alone

- Hypertension alone

- Proteinuria and hypertension

- Neither proteinuria or hypertension

Symptoms preceding seizure (occurred in 59\% of cases)

- Headache

- Visual disturbances

- Epigastric pain

- All of the above

Table 3 Differential diagnosis of seizures in pregnancy

Primary generalised epilepsy

Subarachnoid haemorrhage

Hypoglycaemia

Thrombotic thrombocytopenic purpura

Amniotic fluid embolism

Central venous sinus thrombosis

Water intoxication

Phaeochromocytoma

Local anaesthetic toxicity (for example, epidural)

Overdose (for example, tricyclic antidepressants)

Table 4 Complications of eclampsia $(n=383)(\%)$

\begin{tabular}{ll}
\hline Required ventilation & $87(23)$ \\
$\begin{array}{l}\text { Disseminated intravascular coagulation (not } \\
\text { HELLP) }\end{array}$ & $33(9)$ \\
HELLP & $27(7)$ \\
Renal failure & $24(6)$ \\
Pulmonary oedema & $18(5)$ \\
Acute respiratory distress syndrome & $7(1.8)$ \\
Cerebrovascular accident & $7(1.8)$ \\
Cardiac arrest & $6(1.6)$ \\
Death & $7(1.8)$ \\
\end{tabular}

upper quadrant pain should have their blood pressure checked and urine analysis performed. $^{7}$

Table 3 details the differential diagnosis of seizures in pregnancy.

\section{Complications}

In the UK Eclampsia Trial, ${ }^{1} 1.8 \%$ of patients died and $35 \%$ had at least one major complication (see table 4).

Preterm and antenatal eclampsia seem to be the most severe. Stillbirth and neonatal death rates were 22.2 and 34.1 per 1000 deliveries respectively. Overall, one in 14 offspring of women with eclampsia died.

In the UK, cerebral haemorrhage is the most common cause of death in eclampsia and pre-eclampsia. ${ }^{8-10}$ The cerebral manifestations are similar to hypertensive encephalopathy with thrombosis and fibrinoid necrosis of cerebral arterioles, diffuse microinfarcts, and petechial haemorrhages in the brain. ${ }^{245}$ However, approximately $20 \%$ of women with eclampsia have a systolic blood pressure of less than $140 \mathrm{~mm} \mathrm{Hg}$ or a DBP of less than $90 \mathrm{~mm}$ $\mathrm{Hg}$ around the time of the seizure. ${ }^{11}$ Retinal changes of hypertensive encephalopathy are rarely seen. ${ }^{2}$

As intravascular volume depletion is accompanied by intense vasospasm, these patients are at increased risk of pulmonary oedema from excessive fluid replacement. Conversely, they are at risk of hypovolaemia even from the normal blood loss associated with delivery. ${ }^{2}$

Pulmonary oedema may be attributable to a combination of increased capillary permeability, low colloid osmotic pressure, and pulmonary endothelial damage. Renal complications 
Table 5 Immediate management of eclampsia

- Summon senior A\&E and obstetric staff

- Secure airway and administer high flow oxygen

- Place wedge under right hip or nurse in left lateral position

- Secure intravenous access and draw blood for FBC, U\&Es, LFTs, clotting screen, cross match, and Kleihauer test if abruption suspected

- Control seizures

- Control hypertension

- Monitor vital signs including BP, ECG, RR, $\mathrm{SaO}_{2}$ and fetal heart rate

- Catheterise bladder, monitor urine output, and test urine for protein

Table 6 Drug treatment in eclampsia ${ }^{4}$

\begin{tabular}{|c|c|c|c|}
\hline Drug & Dose & Onset & Side effects \\
\hline \multicolumn{4}{|l|}{ Seizure control } \\
\hline $\begin{array}{l}\text { Diazepam } \\
\text { or }\end{array}$ & $5-10 \mathrm{mg}$ slow iv bolus & & \\
\hline Lorazepam & $2-4 \mathrm{mg}$ slow iv bolus & & \\
\hline $\begin{array}{l}\text { Magnesium } \\
\text { sulphate }\end{array}$ & $\begin{array}{l}4-6 \mathrm{~g} \text { slow iv bolus } \\
\text { over } 5 \text { minutes then } \\
1-2 \mathrm{~g} / \mathrm{h} \text { iv infusion }\end{array}$ & & $\begin{array}{l}\text { Loss of patellar reflexes } \\
\text { Drowsiness } \\
\text { Slurring of speech } \\
\text { Flushing } \\
\text { Muscle weakness } \\
\text { Respiratory depression }\end{array}$ \\
\hline \multicolumn{4}{|c|}{ Blood pressure control } \\
\hline Hydralazine & $\begin{array}{l}5 \text { mg slow iv bolus } \\
\text { every } 20-30 \mathrm{~min}\end{array}$ & $10 \mathrm{~min}$ & $\begin{array}{l}\text { Headache, tremor, nausea, } \\
\text { vomiting, tachycardia }\end{array}$ \\
\hline \multicolumn{4}{|r|}{$x_{0}$} \\
\hline Labetalol & $\begin{array}{l}10 \mathrm{mg} \text { slow iv bolus } \\
\text { doubling every } 10- \\
20 \mathrm{~min} \text { to } \max 300 \mathrm{mg} \text { total } \\
\text { or } 1-2 \mathrm{mg} / \mathrm{min} \text { iv infusion }\end{array}$ & $5-10 \mathrm{~min}$ & $\begin{array}{l}\text { Bradycardia (fetal), } \\
\text { maternal flushing, nausea }\end{array}$ \\
\hline \multicolumn{4}{|l|}{ Fluids } \\
\hline Crystalloid & $1-2 \mathrm{ml} / \mathrm{kg} / \mathrm{h}$ with monitoring of & rine output & \\
\hline
\end{tabular}

iv=intravenous.

include glomerular swelling and fibrin deposition resulting in glomerular capillary endotheliosis. Oliguria is common and this can progress to acute tubular necrosis. ${ }^{2}$

Hepatic dysfunction may result from periportal hepatic necrosis, subcapsular haemorrhages or fibrin deposition in hepatic sinusoids. In very rare cases, fatal hepatic rupture may occur. ${ }^{2}$ Hepatic dysfunction may form part of the HELLP syndrome, which complicates $0.3 \%$ of all pregnancies and up to $20 \%$ of women with severe pre-eclampsia. The syndrome comprises haemolysis, increased liver enzymes, and low platelets with epigastric or right upper quadrant pain. ${ }^{12}$ This represents a life threatening complication and requires prompt delivery.

Disseminated intravascular coagulation occurs in $7 \%$ of patients with eclampsia but the cause is unclear. ${ }^{2}$

Fetal complications are thought to arise as a result of placental hypoperfusion. These include high fetal loss rate, intrauterine growth retardation, small for dates infants and increased perinatal mortality. The oxyhaemo- globin dissociation curve is shifted to the left in pre-eclampsia, reducing oxygen delivery to the fetus. ${ }^{2}$

Placental abruption may accompany eclampsia.

\section{Aims of treatment}

Management of pre-eclampsia/eclampsia consists of prevention or treatment of seizures, control of blood pressure and ultimately, delivery of the infant. ${ }^{13-15}$ Table 5 summarises immediate management of eclampsia.

Sixty per cent of maternal deaths in this condition are attributable to cerebral haemorrhage and a blood pressure of more than 170/110 mm $\mathrm{Hg}$ should be treated urgently but maintained above $130 / 90 \mathrm{~mm} \mathrm{Hg}$ to avoid acute reduction of placental perfusion. ${ }^{4}$ Delivery is indicated urgently if there is evidence of severe, progressive disease such as headache, blurred vision, scotomata, epigastric pain, DBP greater than $110 \mathrm{~mm} \mathrm{Hg}$, clonus, coagulopathy, raised creatinine, or liver enzymes. ${ }^{4}$ Table 6 summarises drug treatment of eclampsia.

\section{CONTROL OF SEIZURES}

Previous studies in the UK reported diazepam and phenytoin as the drugs of choice for treatment of eclamptic seizures. ${ }^{16}{ }^{17}$ Both were commonly used and effective in the treatment of other forms of seizure and phenytoin had the advantage of having little sedative effect. First line measures to control seizures remain diazepam or diazemuls $5-10 \mathrm{mg}$, or lorazepam 2-4 mg given as a slow intravenous bolus. Chlormethiazole has largely been abandoned because of risks of oversedation, loss of airway reflexes, respiratory depression, and fluid overload. By comparison, magnesium sulphate has been first line treatment in the USA and South Africa for many years and is gaining acceptance as the treatment of choice in the UK. ${ }^{16-18}$

The Collaborative Eclampsia Trial ${ }^{19}$ was an international multicentre randomised trial involving 1680 women with eclampsia. The trial was divided into two arms. The first compared magnesium sulphate with diazepam and the second compared magnesium sulphate with phenytoin in the prevention of recurrent seizures. Maternal and neonatal morbidity and mortality were the outcome measures. Table 7 summarises the results.

This study concluded that magnesium sulphate should be the drug of choice for eclampsia. Phenytoin appeared to cause more

Table 7 The Collaborative Eclampsia Trial ${ }^{18}$

\begin{tabular}{lllllll}
\hline Complications & $\begin{array}{l}\text { Magnesium } \\
\text { sulphate (\%) }\end{array}$ & $\begin{array}{l}\text { Diazepam } \\
(\%)\end{array}$ & Significance & $\begin{array}{l}\text { Magnesium } \\
\text { sulphate (\%) }\end{array}$ & $\begin{array}{l}\text { Phenytoin } \\
(\%)\end{array}$ & Significance \\
\hline Recurrent fits & 13.2 & 27.9 & S & 5.7 & 17.1 & S \\
Maternal mortality & 3.8 & 5.1 & NS & 2.6 & 5.2 & NS \\
Perinatal mortality & 24.8 & 22.4 & NS & 26.1 & 30.7 & NS \\
Ventilation & 5.5 & 6.0 & NS & 14.9 & 22.5 & S \\
Respiratory depression & 7.7 & 7.3 & NS & 8.2 & 11.6 & NS \\
Pneumonia & 2.0 & 3.1 & NS & 3.9 & 8.8 & S \\
ITU admission & 14.3 & 16.6 & NS & 16.7 & 25.1 & S \\
Blood transfusion & 15.1 & 20.1 & NS & 19.7 & 27.0 & S \\
Neonatal intubation & 11.3 & 15.7 & NS & 12.7 & 23.9 & S \\
SCBU admission & 46.5 & 50.2 & NS & 31.7 & 43.6 & $\mathrm{~S}$ \\
\hline
\end{tabular}

NS = non-significant, $S=$ significant. 
maternal and neonatal morbidity and diazepam and phenytoin were associated with increased recurrence of seizures compared with magnesium sulphate.

Magnesium sulphate does not seem to be an anticonvulsant but is known to be a potent cerebral vasodilator. It is thought to reverse cerebral vasoconstriction by blocking calcium influx through the NMDA ( $N$-methyl-Daspartate) subtype of the glutamate channel. ${ }^{2}$ Two prospective, randomised, controlled trials using cranial Doppler ultrasound examination of cerebral blood flow have supported this explanation..$^{20} 21$

Magnesium sulphate may also have a role in the prophylaxis of seizures in pre-eclampsia. ${ }^{22}$

Magnesium sulphate is administered in a loading dose of 4 to $6 \mathrm{~g}$ given as a slow intravenous bolus (for example, four $2 \mathrm{ml}$ ampoules of $50 \%$ solution made up to $20 \mathrm{ml}$ with $5 \%$ dextrose or sterile water, given over five minutes). This loading dose should be followed by a maintenance infusion of 1 to $2 \mathrm{~g}$ per hour. The patient should be monitored carefully for clinical signs of magnesium toxicity, particularly loss of patellar reflexes, drowsiness, flushing, slurring of speech, muscle weakness and respiratory depression, which may herald respiratory (or cardiorespiratory) arrest. Level of consciousness, respiratory rate and effort and the presence of patellar reflexes should be frequently and regularly recorded during the infusion. If toxicity is suspected, the infusion should be discontinued and if required, calcium gluconate $(10 \mathrm{ml}$ of $10 \%$ solution) should be given. Magnesium sulphate increases sensitivity to non-depolarising neuromuscular blocking agents such as vecuronium. Fasciculations may not occur after suxamethonium. $^{2}$

CONTROL OF BLOOD PRESSURE

Hydralazine is known to be effective for controlling hypertension in pre-eclampsia/ eclampsia. ${ }^{11}$ After an intravenous bolus, effects are seen by 10 minutes and are maximal by 20 minutes. Its duration of action is six to eight hours. Side effects include hypotension, tachycardia, tremor, headache, nausea, and vomiting. Unfortunately, this may mimic impending eclampsia. Neonatal thrombocytopenia has also been reported in association with the use of hydralazine.

Labetalol is being used more frequently in this setting. Its onset of action is more rapid than hydralazine, reflex tachycardia does not occur and there are few maternal or neonatal side effects. It was found to safely lower mean arterial pressure in a randomised controlled double blind trial of 152 women with pregnancy induced hypertension. ${ }^{23}$

Under invasive blood pressure monitoring, blood pressure should be controlled aiming for a DBP of 90 to $100 \mathrm{~mm} \mathrm{Hg}$. Give hydralazine $5 \mathrm{mg}$ slow intravenous bolus and repeat every 20 to 30 minutes as indicated, or, give labetalol $10 \mathrm{mg}$ slow intravenous bolus, doubling the dose every 10 minutes (for example, 10, 20, 40, etc to a maximum total of $300 \mathrm{mg}$ ) or start an intravenous infusion of $1-2 \mathrm{mg} / \mathrm{min}$ until the required $\mathrm{DBP}$ is reached.

\section{FLUID MANAGEMENT}

Pre-eclampsia/eclampsia seems to be a high cardiac output state associated with an inappropriately high peripheral resistance. It is also associated with haemoconcentration, reduction and central redistribution of plasma volume. ${ }^{24}$ Volume expansion seems to produce transient benefit but there are no studies to suggest that this is accompanied by reduced maternal or fetal morbidity or mortality. ${ }^{2}$

Controversy exists as to whether central venous pressure monitoring is helpful as it may not accurately reflect pulmonary capillary wedge pressure. Most cases are managed without such monitoring. One study, using invasive monitoring in 49 patients with severe preeclampsia, demonstrated normal or high cardiac output in the presence of normal wedge and central venous pressure, and inappropriately high systemic vascular resistance. ${ }^{24}$ It concluded, that because filling pressures were normal, fluid should be given cautiously to avoid precipitating pulmonary oedema. Hypotension and fetal distress have been reported in pre-eclamptic patients given epidural analgesia or hydralazine without prior fluids. In view of the increased risk of pulmonary oedema, a suggested fluid regimen is of crystalloids given at $1-2 \mathrm{ml} / \mathrm{kg} / \mathrm{h}$ with careful monitoring of urine output. $^{24}$

\section{URGENT TRANSFER}

Arrange urgent transfer to an obstetric unit for delivery.

\section{Conclusion}

Eclampsia remains a major cause of maternal and fetal morbidity and mortality in the UK. $\mathrm{Up}$ to one third of cases may present to the A\&E department. A variety of presentations may occur. The diagnosis needs to be considered in any patient at more than 20 weeks gestation with any suspicious features. Prompt recognition and appropriate management minimises morbidity and mortality for both mother and child. In view of recent changes in the treatment of eclampsia, A\&E departments, together with their local obstetricians, should review their treatment guidelines and ensure the appropriate drugs are readily available.

I thank Mr M Gordon and Dr T Parke for their helpful comments in the preparation of this review. Philip Munro initiated, researched, wrote and revised the manuscript and will act as guarantor.

Conflict of interest: none.

Funding: none.

1 Douglas KA, Redman CWG. Eclampsia in the United Kingdom. BMF 1994;309:1395-400.

2 Mushambi MC, Halligan AW, Williamson K. Recent developments in the pathophysiology and management of pre-eclampsia. Br f Anaesth 1996;76:133-48.

3 Saftlas AF, Olson DR, Franks AL, et al. Epidemiology of pre-eclampsia and eclampsia in the United States, 1979-1986. Am f Obstet Gynecol 1990;163:460-5.

4 Probst BD. Hypertensive disorders of pregnancy. Emerg Med Clin North Am 1994;12:73-89.

5 Brown CEL, Purdy P, Cunningham FG. Head computed tomographic scans in women with eclampsia. Am $\mathcal{f}$ Obstet Gynecol 1988:159:915-20.

6 Kupfeminc MJ, Eldor A, Steinman N, et al. Increased frequency of genetic thrombophilia in women with complications of pregnancy. $N$ Engl f Med 1999;340:9-13. 
7 Barry C, Fox R, Stirrat G. Upper abdominal pain in pregnancy may indicate pre-eclampsia. BMF 1994;308: 1562-3.

8 Department of Health, Welsh Office, Scottish Office Home and Health Department, Department of Health and Social Security, Northern Ireland. Report on confidential enquiries into maternal deaths in the United Kingdom 1985-1987. London: HMSO, 1991.

9 Department of Health, Welsh Office, Scottish Office Home and Health Department, Department of Health and Social Security, Northern Ireland. Report on confidential enquiries into maternal deaths in the United Kingdom 1988-1990. London: HMSO, 1994.

10 Department of Health, Welsh Office, Scottish Office Home and Health Department, Department of Health and Social Security, Northern Ireland. Report on confidential enquiries into maternal deaths in the United Kingdom 1991-1993. London: HMSO, 1996.

11 National high blood pressure education program working group report on high blood pressure in pregnancy. $A m \mathcal{F}$ Obstet Gynecol 1990;163:1689-712.

12 Weinstein L. Syndrome of hemolysis, elevated liver enzymes, low platelet count: a severe consequence of hypertension on pregnancy. Am F Obstet Gynecol 1982;142: 159-67.

13 Abbott JT. Acute complications related to pregnancy. In: Rosen P, Barkin R, eds. Emergency medicine: concepts and clinical practice. 4th Ed. St Louis: Mosby, 1998.

14 Hansen WF, Hansen AR. Problems in pregnancy. In: Tintinalli JE, Ruis E, Krome RL, eds. Emergency medicine: a comprehensive study guide. 4th Ed. New York: McGraw-Hill, 1996.
15 Nash P, Price J. Obstetric emergencies. In: Skinner D, Swain A, Peyton $\mathrm{R}$, et al. Cambridge textbook of accident and Press, 1997.

16 Hutton JD, James DK, Stirrat GM, et al. Management of severe pre-eclampsia and eclampsia by UK consultants. $\mathrm{Br}$ f Obstet Gynaecol 1992;99:554-6.

17 Gulmezoglu AM, Duley L. Use of anticonvulsants in eclampsia and pre-eclampsia: survey of obstetricians in the United Kingdom and Republic of Ireland. BMF 1998;316: 975-6.

18 Robson SC. Magnesium sulphate: the time of reckoning. $\mathrm{Br}$ f Obstet Gynaecol 1996;103:99-102.

19 The Eclampsia Trial Collaborative Group. Which anticonvulsant for women with eclampsia? Evidence from the Collaborative Eclampsia Trial. Lancet 1995;345:1455-63.

20 Naidu S, Payne AJ, Moodley J, et al. Randomised study as $\mathrm{S}$, Pand assessing the effect of phenytoin and magnesium sulphate 6 $1996 ; 103: 111-16$

21 Belfort MA, Moise KJ. Effect of magnesium sulfate on maternal brain blood flow in pre-eclampsia: a randomised, lacebo-controlled study. Am f Obstet Gynecol 1992;167: 661-6.

22 Lucas MJ, Leveno KJ, Cunningham FG. A comparison of magnesium sulfate with phenytoin for the prevention of eclampsia. N Engl FMed 1995;333:201-5.

23 Pickles CJ, Symonds EM, Pipkin FB. The fetal outcome in a randomised double-blind controlled trial of labetalol versus placebo in pregnancy-induced hypertension. Brf Obstet Gynaecol 1989;96:38-43.

24 Mabie WC, Ratts TE, Sibai BM. The central hemodynamics of severe preeclampsia. Am f Obstet Gynecol 1989;161:1443-8.

\section{National Horizon Scanning Centre (NHSC)}

This specialist unit at the University of Birmingham provides advance notice of new and emerging technologies to the Department of Health. The aim is to enable a more coherent and coordinated introduction of new healthcare technologies - that is, all methods used by health professionals to promote health, prevent and treat disease, improve rehabilitation, and long term care. They include pharmaceuticals, medical devices, diagnostic tests and procedures, surgery, rehabilitation, health promotion activities, service delivery, and organisational issues.

If you know of any new or emerging technologies that could be important to the NHS you should let the NHSC know by completing the form on the web site www.hrsc.org.uk/horizon or by writing to: National Horizon Scanning Centre, Department of Public Health and Epidemiology, University of Birmingham, Edgbaston, Birmingham B15 2TT. 